\title{
Assessing and Modeling Student Academic Practices and Performance in First-Year Mathematics Courses in Higher Education
}

\author{
Kim Y. Ward and Chantal D. Larose \\ Eastern Connecticut State University, Willimantic, Connecticut, USA
}

Submitted: April 30, 2019 | Peer reviewed: July 2, 2019 | Accepted: August 21, 2019 | Published: September 16, 2019

\begin{abstract}
Objectives: This study examines the effectiveness of interventions in first-year math courses in higher education. Our goal is to investigate the efficacy of a supplemental support requirement on the passing rates of students in their first-year math courses.
\end{abstract}

Method: We gathered and analyzed data on 3,249 students using descriptive statistics and predicative analytics. We used classification and regression tree algorithms to model the subgroup within our student population who met or exceeded the midterm supplemental support target.

Results: Our investigation revealed that students who met or exceeded the midterm supplemental support target, earned a midterm course grade of at least $D$, and continued to receive supplemental support in the Mathematics Achievement Center had a $99 \%$ chance of passing their first-year math course. Students with midterm grades of $F$ or I had a $67 \%$ chance of passing.

Conclusions: Students' fulfillment of a supplemental support requirement is a key predictor of the passing rates of students in their first-year math courses. The findings emphasize the importance of strengthening students' affective characteristics.

Implication for Theory and/or Practice: This work provides a roadmap for student interventions and increasing student success with first-year mathematics courses.

Keywords: First-year mathematics courses, supplemental support, affective characteristics, higher education

\section{Introduction and Literature Review}

Research shows that the vast majority of college drop-out occurs within the first two years of collegiate experience (Kwenda, 2014). With the passage of Connecticut Public Act 12-40 in 2012, an act concerning college readiness and completion, which limited developmental mathematics courses to at most one remedial course, embedded courses (college-level courses with embedded remediation) and college-level courses, it became necessary to transform our elementary and intermediate algebra mathematics program (Brakoniecki, Fitzgerald, \& Pritchard, 2013; ConnSCU, 2014). Commencing with the start of the Fall 2014 semester, a new tiered system of instruction, known as the Math Foundations Program, was developed. Two important new features of the Math Foundations Program curriculum include distinguishing between STEM (Science, Technology, Engineering, and Mathematics) and non-STEM disciplines and refining

Author correspondence: wardk@easternct.edu

Suggested Citation: Ward, K. Y. \& Larose, C. D. (2019). Assessing and modeling student academic practices and performance in first-year mathematics courses in higher education. Higher Learning Research Communications, 9(2), Online Version. http://dx.doi.org/10.18870/hlrc.v9i2.451 
course content to reflect topics of study relevant to students' chosen disciplines. Such differentiation of content has become an issue of focus among educational organizations such as the Carnegie Foundation, American Association of Two-Year Colleges, National Developmental Education Association, and Achieving the Dream (Boylan, 2011).

Distinguishing mathematics courses for non-STEM and STEM majors and aligning course content with the student's major are two approaches to increasing the student completion rate. These changes minimize attrition and provide a more structured, coherent, and relevant pathway to success (Ganga, Mazzariello, \& Edgecombe, 2018). The content of each course in the Math Foundations Program covers relevant topics that prepare students for their subsequent math course(s). For example, students majoring in non-STEM disciplines do not need the mathematical skills of performing synthetic division or solving a linear system of three equations and three unknowns. Groundwork for the alignment of the course content involved reviewing various textbooks from other subject areas, such as chemistry, physics, biology, accounting, economics, business, and nursing, meeting with faculty who teach these subjects, and analyzing subsequent math course(s).

Since completion of a mathematics requirement can be a stumbling block for students from all disciplines, the mission of the Math Foundations Program is to strengthen the math preparedness of both non-STEM and STEM students by teaching math skills and math concepts and using technology appropriate for each designated discipline. We believe that fulfilling this mission will yield an increase in the number of students who successfully complete their first year of college. To attain student success, the design of the Math Foundations Program is based on teaching and learning strategies research. Mathematics is a challenging subject for many, with several factors affecting students' academic performance. These include inappropriate placement into one's first college math course, lack of academic preparedness for college-level math coursework, learned helplessness, learning disabilities, and the cost of math textbooks and access codes for math management systems (Hodara, 2013; Rutschow \& Schneider, 2011; Schak, Metzger, Bass, McCann, \& English, 2017; Senack, Donoghue, Grant, \& Steen, 2016; The IRIS Center, 2017). Research has provided new insights into effective methods for learning and teaching mathematics. Learning specialist Dr. Paul Nolting has been assessing mathematics learning strategies for over 25 years. His research addresses various math-learning issues ranging from inadequate study skills to learning disabilities. Dr. Nolting argues that studying math requires a different methodology. Students must understand and recall the subject matter, process new material, and apply old and newly acquired knowledge to solve problems and learn (Nolting, 2008). The sequential nature of math coupled with its own vocabulary, need for consistent and persistent studying, and the speed at which math is taught in higher education create major problems for students.

Research has revealed that the quality of instruction and affective characteristics are critical factors contributing to success in math (Anthony \& Walshaw, 2009; Bloom, 1976; Charalambos \& Hill, 2012; Hodara, 2011; Hodara, 2013; Nolting, 2008; Rutschow \& Schneider, 2011; The IRIS Center, 2017). Quality of instruction addresses teacher knowledge, teaching style, curriculum, and curricular materials such as textbooks, software and supplemental materials, and activities (Charalambos \& Hill, 2012; Raudenbush, 2008; The IRIS Center, 2017). Affective characteristics have been defined in numerous ways in the literature. They have been defined in terms of academic activities such as study skills, test-taking skills, and learning styles (Boylan, 2011; Cornick, Guy, \& Beckford, 2015; Nolting, 2008). At other times they have been defined using personal attributes such as one's level of motivation to engage in the learning process, selfefficacy, attitudes toward learning, desire to seek assistance, confidence in learning mathematics, anxiety, perceived usefulness of mathematics, and learned helplessness (Guy, Cornick, \& 
Beckford, 2015; Harvey \& Horton, 1977; Olango, 2015; Reyes, 1984; Sedlacek, 2004; The IRIS Center, 2017). The design of the Math Foundations Program addresses quality of instruction, focusing on the curriculum, curricular materials, and students' affective characteristics, both academic activities and personal traits. Student recognition of their role in attaining math proficiency is necessary to improve their success (Anthony \& Walshaw, 2009).

\section{Design of the Math Foundations Program}

Enrollment at the institution in which this study was conducted was approximately 5,000 students. Among all degree-seeking undergraduate students in Fall 2018, the average SAT math score was 550; however, we should state that the SAT is optional for admissions. Approximately $35 \%$ of full-time students entering in Fall 2018 were first generation students and $30.8 \%$ were minority students. Research suggests that students who complete their coursework faster are more likely to complete college (Cornick et al., 2015). Studies show that first generation and minority students are more likely to be enrolled in developmental education courses and less likely than their peers to graduate in four years or to graduate at all (Ganga et al., 2018; Treisman, 1992; Zachry \& Schneider, 2010). Therefore, improvement of supplemental support is needed to strengthen persistence and retention, particularly for these students (Berry, Thunder, \& McClain, 2011; Cohen \& Kelly, 2019; Hattie \& Timperly, 2007; Koirala, Davis, \& Cid, 2010; Wright, 2009). Researchers have noted the importance of teaching to become independent, self-directed learners (ConnCas, 2013; Ganga et al., 2018; Zachry \& Schneider, 2010). Self-directed learners are able to "assess the demands of a task, evaluate their own knowledge and skills, plan their approach, monitor their progress, and adjust their strategies as needed" (Ambrose, Bridges, Lovett, DiPietro, \& Norman, 2010, p. 191). Thus, we created the Math Foundations Program as an avenue for producing self-directed learners. Developmental students need multiple instructional approaches, including: integrating lectures with math study skills, encouraging group work, using online tools, tailoring tutoring to unique learning styles, and frequently offering various forms of assessments (Boylan, 2011; Kezar, Gehrke, \& Bernstein-Sierra, 2017; Nolting, 2008). The more we can inform our students of their learning goals and responsibilities, the better we can evaluate their performance while simultaneously increasing success of both student and professor (Grunert, Millis, \& Cohen, 2008).

As mandated by the Connecticut Public Act 12-40, the Math Foundations Program is a tiered system of instruction for first-year math courses. This tiered system of instruction is categorized into one of three levels: intensive, embedded, and college. The intensive level contains a developmental math course designed for students who are below the skill level required for success in college-level work. The math course satisfying the criteria is Algebra Essentials, which prepares students for further mathematical studies in both non-STEM and STEM disciplines. The class size is limited to 20 students, which allows instructors more opportunities to provide individualized guidance. This course covers topics in elementary algebra and intermediate algebra and utilizes a free, open online textbook and homework management system which encompasses common homework assignments. The use of graphing calculators is also required. Students successfully completing this course then enroll in Math for Liberal Arts Plus, Number Systems Plus, or Precalculus Mathematics Plus as determined by their major.

The embedded level contains courses designed for students who are likely to succeed in college-level work with supplemental support. Three math courses meet the criteria for this level, Math for Liberal Arts Plus, Number Systems Plus, and Precalculus Mathematics Plus. The enrollment limit for each course is 25 students, again allowing more opportunities for personalized attention. Math for Liberal Arts Plus and Number Systems Plus are both non-STEM courses, each 
earning a student four credits towards graduation. Math for Liberal Arts Plus is an accelerated course which offers integrated just-in-time intermediate algebra support. Topics covered include voting theory, financial mathematics, linear programming, identification numbers, and statistics. This course uses a customized textbook and requires use of a graphing calculator. Upon successful completion of this course, students will have met the university's liberal arts core Tier I math requirement for their major. Number Systems Plus is designed and intended for Elementary Education and Early Childhood Education students only. Topics include elementary number theory, non-decimal systems, numeration, and computational algorithms in the elementary school. This course will integrate algebra topics covered on the Praxis II exam required for Elementary Education certification. Students successfully completing this course then enroll in Geometry and Probability, a subsequent course designed for future elementary school teachers. Students majoring in STEM disciplines enroll in Precalculus Mathematics Plus. This accelerated course offers integrated just-in-time intermediate through college algebra support and covers exponential and logarithmic functions, trigonometry, and analytic geometry. This is a five-credit course, with all credits counting toward graduation. It requires a graphing calculator and utilizes a free, open online textbook and homework management system which contains common homework assignments. Students successfully completing this course then enroll in Calculus I.

There are two college-level math courses, Math for Liberal Arts and Precalculus Mathematics. Non-STEM students enroll in Math for Liberal Arts, a three-credit course with a class size limited to 35 students. Topics covered in this course include voting theory, financial mathematics, and statistics. Upon successful completion of this course, students have met the university's liberal arts core Tier I math requirement for their major. Precalculus Mathematics is a course for students intending to pursue STEM programs. The topics covered included inverse functions, exponential and logarithmic functions, trigonometry, and analytic geometry. The class size is limited to 30 students. Table 1 provides a summary of the courses included in each level of the tiered system of instruction and whether they serve STEM or non-STEM disciplines.

Table 1. Summary of Courses Included in Each Level of the Tiered System.

\begin{tabular}{lll}
\hline Level & Math Course & Discipline \\
\hline Intensive & Algebra Essentials & Non-STEM and STEM \\
\multirow{2}{*}{ Embedded } & Math for Liberal Arts Plus & Non-STEM \\
& Number Systems Plus & Non-STEM \\
& Precalculus Mathematics Plus & STEM \\
College & Math for Liberal Arts & Non-STEM \\
& Precalculus Mathematics & STEM \\
\hline
\end{tabular}

Each of these courses in the Math Foundations Program have multiple sections. To promote consistency throughout all sections of the same course, common syllabi and coverage of common content have been established for each individual course. Currently, the Math Foundations Program coordinator prepares and disseminates all common materials. As at many universities, courses in the Math Foundations Program are taught largely by part-time faculty. The Math Foundations Program coordinator, Math Department chair, and/or assistant chair conducts workshops and individual work sessions with all instructors teaching these courses to promote quality of instruction.

Supported by research, we use multiple measures to assess postsecondary math placement (Schak et al., 2017). Math placement is determined by one of the following: SAT math 
score, ACT score, or the department's Accuplacer exam score. Of these three options, the highest score determines a student's math placement. A summary of the math placement results is given in Table 2. We observe that math placement into the college-level tier is consistently and sufficiently lower than math placement into the intensive and embedded levels, hence increasing the number of sections being offered and the need for part-time faculty. The placement results are not surprising, as $66 \%$ of high school graduates entering college are academically underprepared for college-level work (Whiton, Rethinam, \& Preuss, 2018).

Table 2. Summary of Math Placement Results by Levels in the Tiered System.

\begin{tabular}{llll}
\hline Year & Intensive Level & Embedded Level & College Level \\
\hline 2014 & $22 \%$ & $53 \%$ & $23 \%$ \\
2015 & $36 \%$ & $45 \%$ & $19 \%$ \\
2016 & $33 \%$ & $45 \%$ & $21 \%$ \\
2017 & $42 \%$ & $41 \%$ & $16 \%$ \\
2018 & $45 \%$ & $43 \%$ & $11 \%$ \\
\hline
\end{tabular}

Methods

The present study focuses on three first-year courses in the Math Foundations Program; Algebra Essentials, a developmental course, and two accelerated courses: Math for Liberal Arts Plus and Precalculus Mathematics Plus. In addition to the use of common syllabi and coverage of common content, two more features have been added for these courses. First, common final exams have been established for each of these individual courses. The common final exams account for $30 \%$ of the final course grades in Math for Liberal Arts Plus and $25 \%$ in both Algebra Essentials and Precalculus Mathematics Plus. Second, all students enrolled in these three courses must complete 18 hours of supplemental support in the university's Mathematics Achievement Center, a free tutoring center. The supplemental support requirement accounts for $10 \%$ of the final course grade. Structured tutoring, which directly connects tutoring with specific courses, is a popular form of supplemental support among developmental educators (Rutschow \& Schneider, 2011). Having students receive supplemental support outside of the classroom is a strategy to improve success in math (Rutschow \& Schneider, 2011; Spaho, 2014). The supplemental support requirement consists of structured tutoring which addresses affective characteristics and must be completed in the Mathematics Achievement Center. To assist students with establishing frequent and consistent study habits, students receive credit for a maximum of three hours per day in the Mathematics Achievement Center, and two target dates are set. To achieve the first target, referred to as the midterm target, students complete nine hours prior to midterm course grade calculation. For the second or final target students complete the remaining nine hours, or more if the student did not meet the first target, prior to the start of the university's final examination period. Failure to complete the supplemental support requirement does not prevent a student from taking their common final exam.

The Mathematics Achievement Center is open 63 hours per week and employs student tutors who undergo a thorough hiring and training process. Each semester the director of the Mathematics Achievement Center visits every classroom for all three of the courses in our study to reiterate the supplemental support requirement, discuss the procedures for students signing in and out of the Mathematics Achievement Center, review services offered in the Mathematics Achievement Center and the logistics of collecting and reporting the number of supplemental support hours completed in the Mathematics Achievement Center. Students are informed of their number of completed hours total every two weeks. While in the Mathematics Achievement Center, students receive various services and engage in several activities to help develop and strengthen 
affective characteristics. The services include one-on-one tutoring, group tutoring, and assistance with math test preparation. The activities include working independently on math homework, both handwritten and computerized assignments, completing topic-specific math worksheets, and borrowing graphing calculators and textbooks.

The objectives of this study were to:

1. Investigate the efficacy of the supplemental support requirement on the passing rates of students in their first-year math courses.

2. Model the subgroup within our student population who met or exceeded the midterm supplemental support target.

3. Provide succinct conclusions that will motivate students to complete the supplemental support requirement.

Following the Institutional Review Board's approved protocol, we collected data on 3,249 students who were enrolled in Algebra Essentials, Math for Liberal Arts Plus, and Precalculus Mathematics Plus between Fall 2014 and Spring 2018. Sixteen percent of students were enrolled in Algebra Essentials, 65\% in Math for Liberal Arts Plus, and 19\% were in Precalculus Mathematics Plus. Ninety percent of all students in our study were freshmen. For each student in this study we collected the following data: the course in which they were enrolled, midterm course grade, final course grade, the number of supplemental support hours completed in the Mathematics Achievement Center by the midterm target and the number of supplemental support hours completed in the Mathematics Achievement Center by the final target. The data were analyzed using descriptive statistics and predicative analytics.

\section{Results}

\section{Descriptive Statistics}

We begin by investigating the relationship between the midterm supplemental support target and the midterm course grade. The percentage, by course, of students completing the midterm supplemental support target of nine hours in the Mathematics Achievement Center was $50 \%$ for Algebra Essentials, $46 \%$ for Math for Liberal Arts Plus, and $58 \%$ for Precalculus Mathematics Plus. We defined the pass rate as the percentage of students earning the letter grade of $D$ or higher. The success rate was defined as the percentage of students earning the letter grade of $\mathrm{C}$ or higher. For each first-year course, Table 3 shows the midterm pass rates, success rates, and supplemental support requirement completion rates between Fall 2014 and Spring 2018.

Table 3. Midterm SSRC Rates, Pass Rates, and Success Rates between Fall 2014 and Spring 2018

\begin{tabular}{|c|c|c|c|}
\hline & $\begin{array}{l}\text { Algebra Essentials } \\
\underline{n=526}\end{array}$ & $\begin{array}{l}\text { Math for Liberal } \\
\text { Arts Plus } \\
\underline{n=2100}\end{array}$ & $\begin{array}{l}\text { Precalculus } \\
\text { Mathematics } \\
\text { Plus } \\
n=623\end{array}$ \\
\hline $\begin{array}{l}\text { Midterm SSRC } \\
\text { Rate }\end{array}$ & $50 \%$ & $46 \%$ & $58 \%$ \\
\hline Pass Rate & $83 \%$ & $83 \%$ & $80 \%$ \\
\hline Success Rate & $73 \%$ & $71 \%$ & $68 \%$ \\
\hline
\end{tabular}


Figure 1 shows a histogram of the midterm supplemental support target of nine hours (540 minutes) represented by the vertical line, with an overlay to the midterm course grade, for all three courses. The colors within each histogram bar represent the distribution of midterm grades earned by the students in that bar. We observe that most students attend the Mathematics Achievement Center close to or more than the midterm supplemental support target of nine hours.

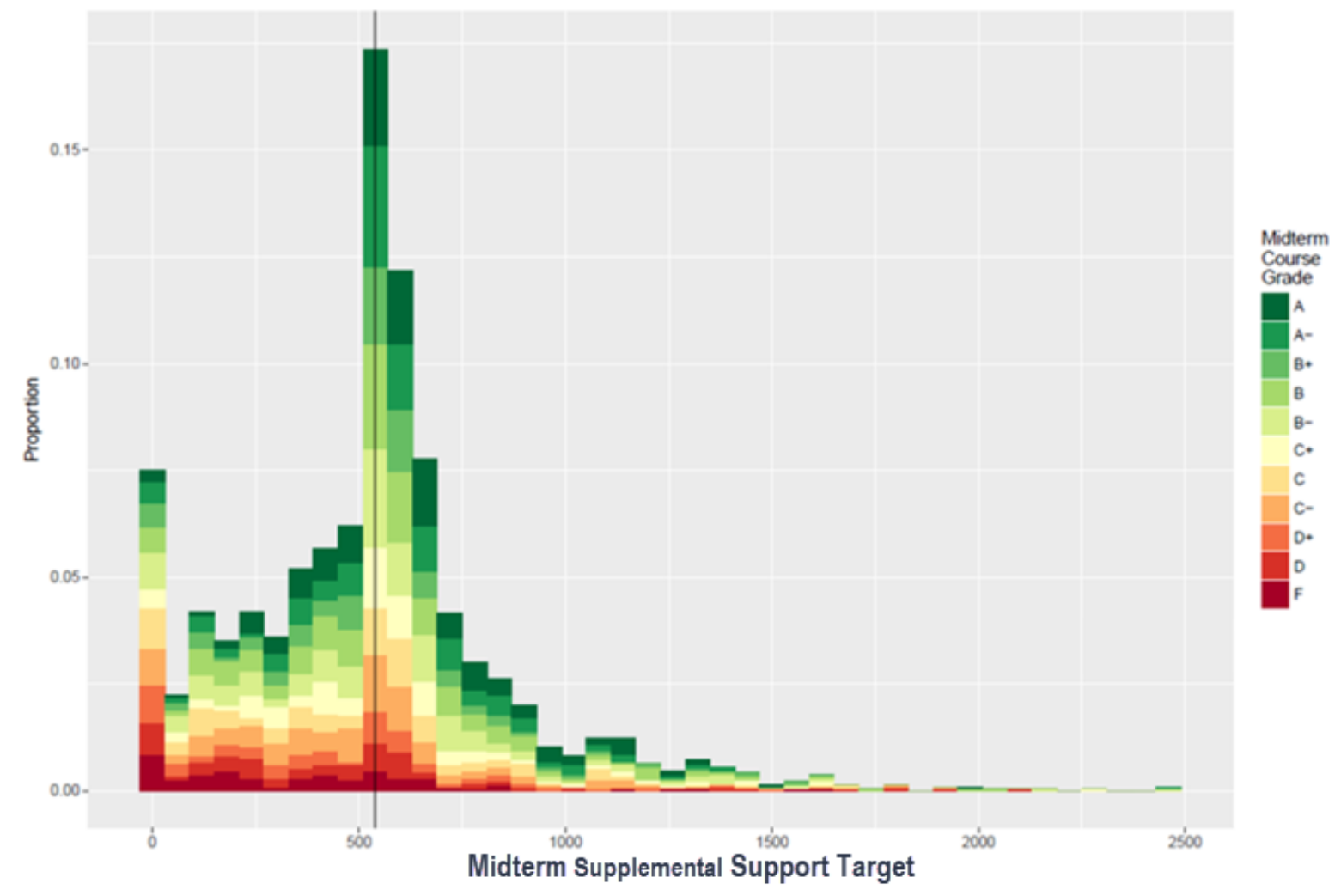

Figure 1. Histogram of the midterm supplemental support target of nine hours (540 minutes) represented by the vertical line, with an overlay of midterm course grades, for all three courses.

In Figure 2 we vertically stretch the bars in Figure 1 so that the heights are equal length with a range between 0 and 1 . In this way, the patterns within each histogram bar become clearer and allow for comparison of the distributions with each bar. This is called a normalized histogram. Figure 2 illustrates a pronounced increase in the proportion of As and Bs in each bar as we progress across the chart from zero toward the midterm supplemental support target of 540 minutes. Thus, we anticipate that the midterm supplemental support target is important to the prediction of midterm course grades. 


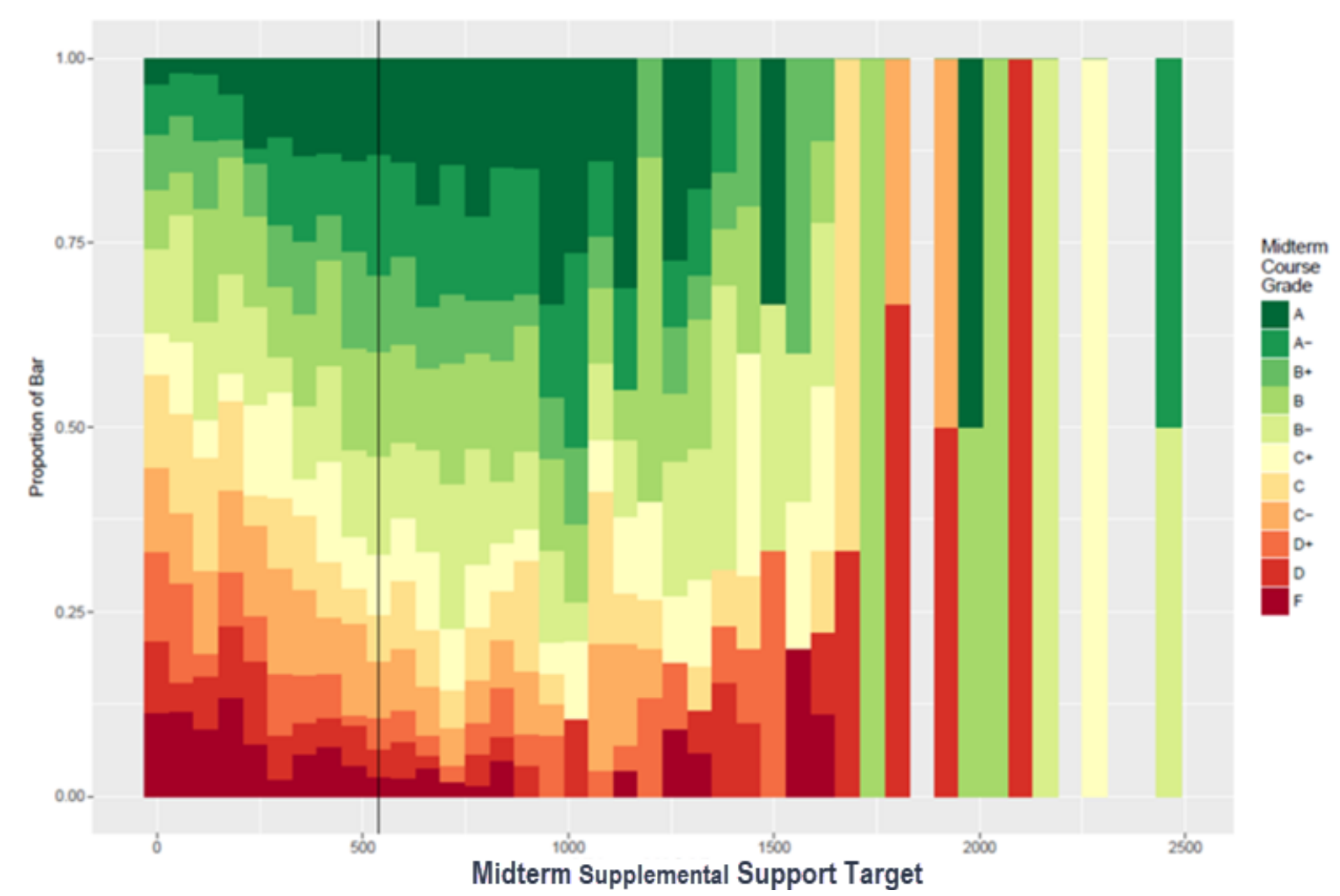

Figure 2. Normalized histogram of the midterm supplemental support target of nine hours (540 minutes) represented by the vertical line, with an overlay of midterm course grades, for all three courses.

Now we examine the relationship between the final supplemental support target and the final course grade. The percentage, by course, of students completing the final supplemental support target of 18 hours in the Mathematics Achievement Center was $45 \%$ for Algebra Essentials, 48\% for Math for Liberal Arts Plus, and 53\% for Precalculus Mathematics Plus. Figure 3 is the normalized histogram of the final supplemental support target of 18 hours (1080 minutes), represented by the vertical line, with an overlay to the final course grade, for all three courses. We see a similar pattern to that of Figure 2, namely that students perform better the closer they are to meeting the final supplemental support target. We anticipate that the final supplemental support target is important in predicting final course grade. 


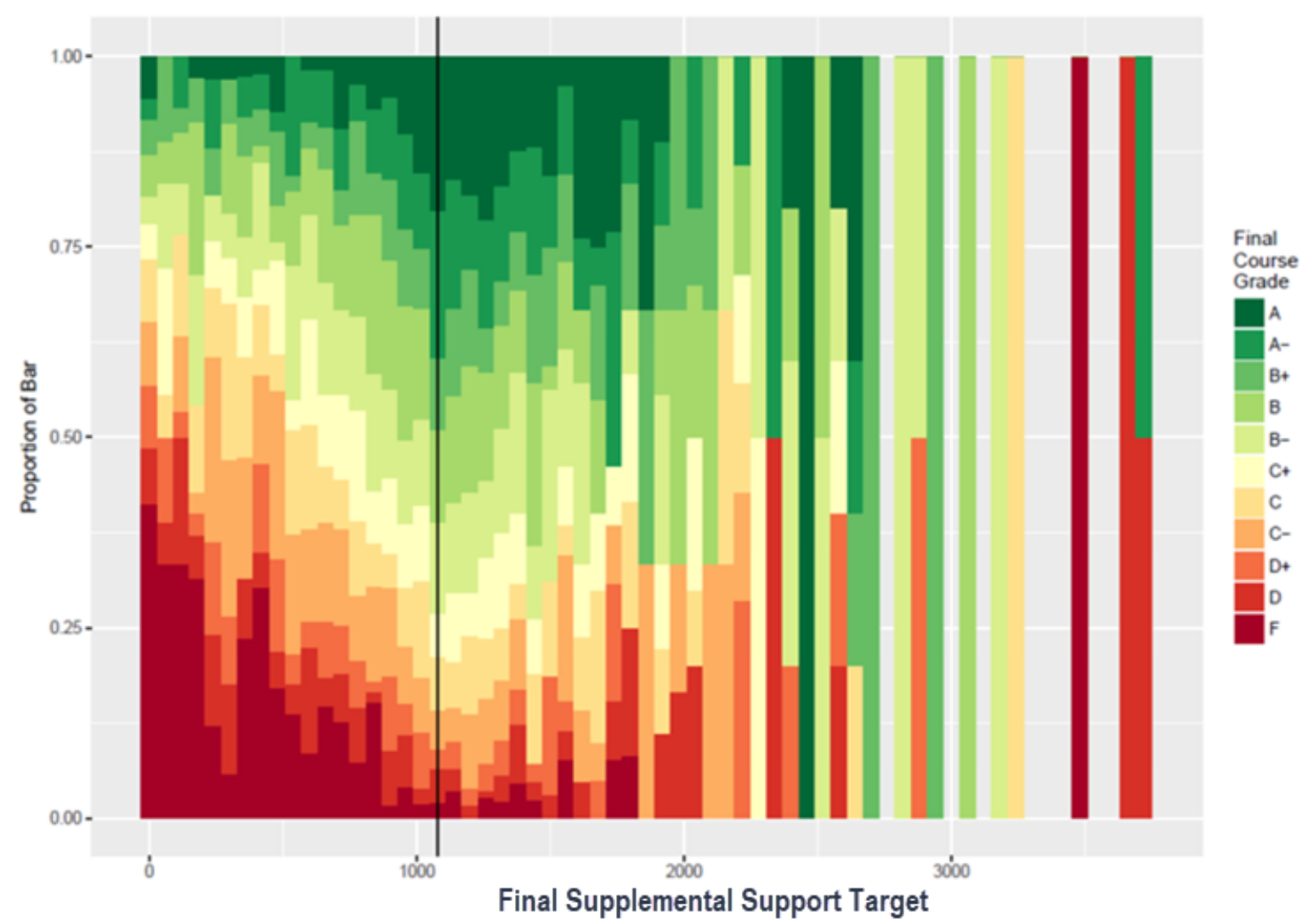

Figure 3. Normalized histogram of the final supplemental support target of 18 hours (1080 minutes) represent by the vertical line, with an overlay of midterm course grades, for all three courses.

In Table 4, for each first-year course, we see the final pass rates, success rates, and supplemental support requirement completion rates between Fall 2014 and Spring 2018. Comparing the results of Tables 3 and 4 we see a slight increase in the pass and success rates for Algebra Essentials and Math for Liberal Arts Plus. However, for Precalculus Mathematics Plus there is a slight decrease, which is explained by the quantity of math content taught and the higher level of difficulty of the math content.

Table 4. Final SSRC Rates, Pass Rates, and Success Rates Between Fall 2014 and Spring 2018

\begin{tabular}{|c|c|c|c|}
\hline & $\begin{array}{l}\text { Algebra } \\
\text { Essentials } \\
\underline{n=526}\end{array}$ & $\begin{array}{l}\text { Math for Liberal } \\
\text { Arts Plus } \\
n=2100\end{array}$ & $\begin{array}{l}\text { Precalculus } \\
\text { Mathematics Plus } \\
n=623\end{array}$ \\
\hline Final SSRC Rate & $45 \%$ & $\overline{48 \%}$ & $53 \%$ \\
\hline Pass Rate & $86 \%$ & $85 \%$ & $79 \%$ \\
\hline Success Rate & $77 \%$ & $76 \%$ & $62 \%$ \\
\hline
\end{tabular}

${ }^{*}$ SSRC = supplemental support requirement completion.

Tables 5, 6, and 7 show the pass and success rates for each individual course between Fall 2014 and Spring 2018. We see fluctuations in the pass and success rates for these individual courses. In Table 5 we see that for Algebra Essentials, which serves both STEM and non-STEM 
disciplines, the pass rates are consistently above $70 \%$ and the success rates above $65 \%$. The pass rates and success rates for Math for Liberal Arts Plus in Table 6, which serves Non-STEM disciplines, are consistently above $73 \%$ and $67 \%$, respectively. As shown in Table 7 more variation exists in the results for Precalculus Mathematics Plus, which is the math course for STEM disciplines.

Table 5. Final Course Pass and Success Rates for Algebra Essentials

\begin{tabular}{llllll}
\hline \multicolumn{2}{l}{ Algebra Essentials } & & & \\
\hline Term & Pass & Success & Term & Pass & Success \\
& Rate & Rate & & Rate & Rate \\
Fall 2014 & $83 \%$ & $75 \%$ & Spring 2015 & $80 \%$ & $73 \%$ \\
Fall 2015 & $91 \%$ & $76 \%$ & Spring 2016 & $74 \%$ & $74 \%$ \\
Fall 2016 & $91 \%$ & $87 \%$ & Spring 2017 & $91 \%$ & $59 \%$ \\
Fall 2017 & $83 \%$ & $77 \%$ & Spring 2018 & $70 \%$ & $65 \%$ \\
\hline
\end{tabular}

Table 6. Final Course Pass and Success Rates for Math for Liberal Arts Plus

\begin{tabular}{llllll}
\hline \multicolumn{2}{l}{ Math for Liberal Arts Plus } & & & \\
\hline Term & Pass & Success & Term & Pass & Success \\
& Rate & Rate & & Rate & Rate \\
Fall 2014 & $87 \%$ & $77 \%$ & Spring 2015 & $83 \%$ & $76 \%$ \\
Fall 2015 & $87 \%$ & $79 \%$ & Spring 2016 & $89 \%$ & $81 \%$ \\
Fall 2016 & $86 \%$ & $80 \%$ & Spring 2017 & $93 \%$ & $80 \%$ \\
Fall 2017 & $82 \%$ & $72 \%$ & Spring 2018 & $73 \%$ & $67 \%$ \\
\hline
\end{tabular}

Table 7. Final Course Pass and Success Rates for Precalculus Mathematics Plus

\begin{tabular}{llllll}
\hline \multicolumn{2}{l}{ Precalculus } & Mathematics Plus & & & \\
\hline Term & Pass & Success & Term & Pass & Success \\
& Rate & Rate & Rate & Rate \\
Fall 2014 & $88 \%$ & $71 \%$ & Spring 2015 & $93 \%$ & $83 \%$ \\
Fall 2015 & $80 \%$ & $62 \%$ & Spring 2016 & $84 \%$ & $63 \%$ \\
Fall 2016 & $75 \%$ & $58 \%$ & Spring 2017 & $78 \%$ & $55 \%$ \\
Fall 2017 & $74 \%$ & $60 \%$ & Spring 2018 & $67 \%$ & $58 \%$ \\
\hline
\end{tabular}

\section{Predictive Analytics}

Our goal is to investigate the efficacy of a supplemental support requirement, which accounts for $10 \%$ of the final course grade, on the passing rates of students in their first-year math courses. We have selected to focus on the subgroup within our student population who met or exceeded the midterm supplemental support target of nine hours. We used the classification and regression tree (CART) algorithm to build a decision tree for predicting the final course outcomes for our subgroup in their first-year math course based on the amount of additional supplemental support students accrued in the Mathematics Achievement Center beyond the midterm target of 540 minutes (Breiman, Friedman, Olshen, \& Stone, 1984; Therneau, Atkinson, \& Ripley, 2017). The CART algorithm creates binary decision trees with exactly two branches at every decision node. The algorithm proceeds by recursively visiting each decision node and selecting the optimal split until no further splits are possible. Results can be summarized in logical if-then statements (Larose \& Larose, 2015, p. 319). Figure 4 contains a visualization of the CART model. The topcenter node represents our subgroup population. The CART model will make divisions with the 
goal of isolating groups of students who passed the course and groups who failed the course. The initial split divides the data into two groups; students with a midterm course grade of $D$ or higher are sent via the leftmost branch and students with a midterm course grade of $F$ or I (incomplete) are sent via the rightmost branch. To alleviate the issue of double-counting midterm supplemental support time when considering final supplemental support time, we create a new variable: Extra Math Center Minutes (ExtraMC Min), which is defined as the additional amount of supplemental support students accrued in the Mathematics Achievement Center beyond the midterm target of 540 minutes. The CART algorithm continues to split the leftmost branch and rightmost branch with the goal of isolating groups of students who passed the course and groups who failed the course based on other variables.

For students with a midterm course grade of $D$ or higher, which is the leftmost branch of our initial split, the next decision node tests whether students' accrued Extra Math Center Minutes is less than 0.5 minutes or is at least 0.5 minutes. The test for Extra Math Center Minutes exceeding 0.5 minutes leads to a terminating branch which gives Rule 1 . The test for Extra Math Center Minutes less than 0.5 minutes yields another decision node test based on the groups of students who passed the course and groups who failed the course, thus leading to terminating branches producing Rules 3 and 4 . For the rightmost branch of the initial split, which represents students with a midterm course grade of F or I, the next decision node tests whether students' accrued midterm Math Center minutes is less than 578 minutes or at least 578 minutes. This decision node test leads to the termination of this branch resulting in Rules 2 and 5.

\section{CART Model for Classifying Final Outcomes in First-Year Math Courses}

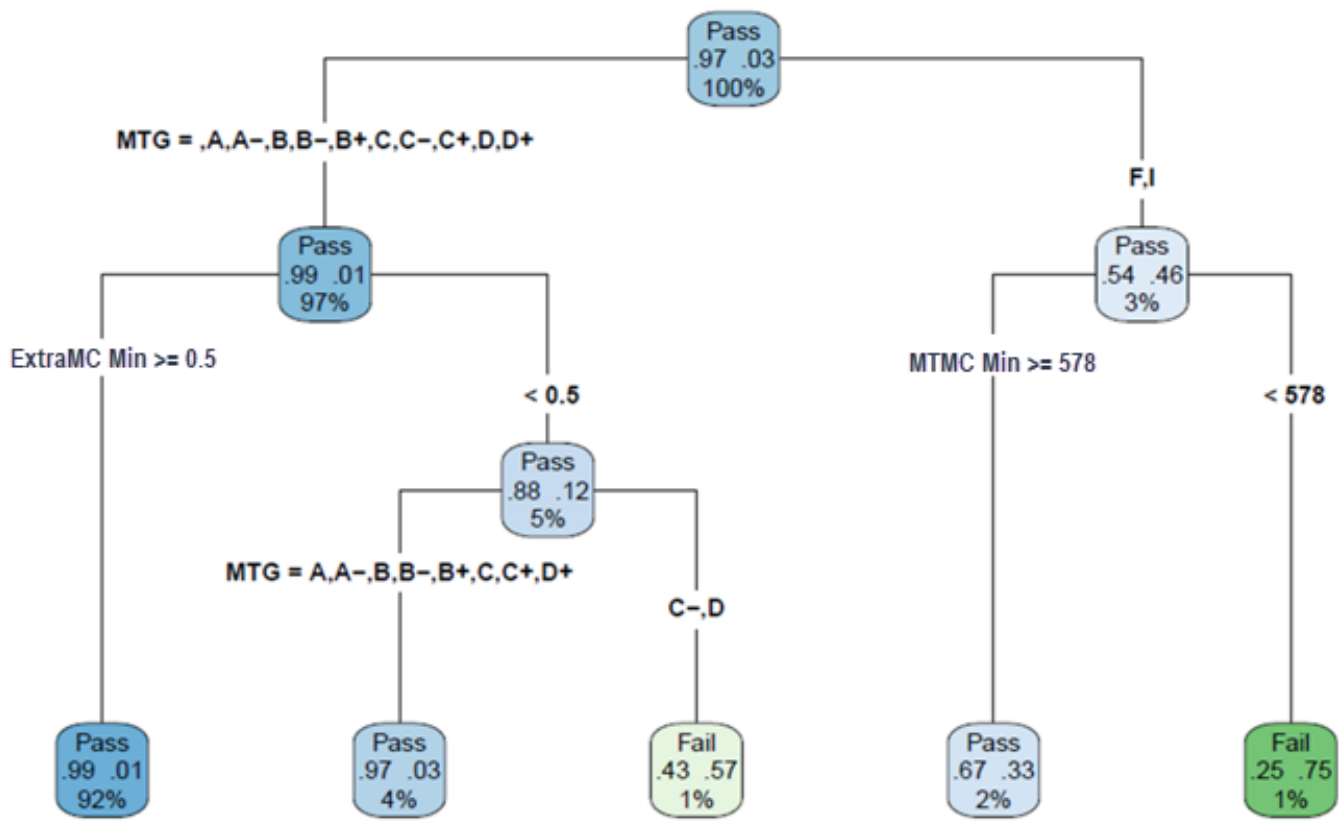

Figure 4. Classifying final course outcomes in first-year math courses. MTG = midterm grade and MTMC Min = midterm target in minutes.

To summarize, in this model, the data suggests that we have five decision rules that classify our students into five groups, described as follows: 
- (Rule 1) If a student earns at least $D+$ for a midterm course grade and receives at least 0.5 minutes of supplemental support in the Mathematics Achievement Center after the midterm target, then the student will pass the course $99 \%$ of the time.

- (Rule 2) If a student earns an F or I (incomplete) for a midterm course grade and receives less than 578 minutes of supplemental support in the Mathematics Achievement Center before the midterm target, then the student will fail the course $75 \%$ of the time.

- (Rule 3) If a student earns at least D+, but not a C- or D, for the midterm course grade and receives less than 0.5 minutes of supplemental support in the Mathematics Achievement Center after the midterm target, then the student will pass the course $97 \%$ of the time.

- (Rule 4) If a student earns a C- or D for the midterm course grade and receives less than 0.5 minutes of supplemental support in the Mathematics Achievement Center after the midterm target, then the student will fail the course $57 \%$ of the time.

- (Rule 5) If a student earns an F or I (incomplete) for a midterm course grade but receives at least 578 minutes of supplemental support in the Mathematics Achievement Center before the midterm target, then the student will pass the course $67 \%$ of the time.

Almost all the students who met the midterm supplemental support requirement $(92 \%)$ fall into Rule 1 . The remaining $8 \%$ are spread across the other four rules. Since so few data points are in those remaining four rules, those four rules are at risk of being influenced by only a few students. However, the risk is mitigated by the fact that the sample size is large $(n=1590)$.

\section{Discussion and Conclusion}

The IRIS Center (2017) reports that "in the United States approximately two-thirds of all students have not mastered expected grade level mathematics concepts and procedures" (p.1). Furthermore, most college drop-outs occur within the first two years of the collegiate experience (Kwenda, 2014). In an effort to address these deficiencies in educational outcomes, the legislature in the state of Connecticut mandated changes leading to a redesign of the mathematics program. The resulting tiered system of instruction has three levels: intensive, embedded and college, which distinguish between STEM and non-STEM majors and align content with the students' majors.

This study focused on the use of supplemental support for three first-year math courses; one intensive-level course, Algebra Essentials, and two embedded-level courses, Math for Liberal Arts Plus and Precalculus Mathematics Plus. Supplemental support is an intervention strategy implemented by several colleges in an effort to strengthen student persistence and retention (Brock et al., 2007; Rutschow \& Schneider, 2011). In this university's Math Foundations Program, the supplemental support requirement consists of completing 18 hours of structured tutoring, which addresses affective characteristics, in the Mathematics Achievement Center on campus. This is a critical feature since teaching students to become independent, self-directed learners is important to their academic success (ConnCas, 2013; Ganga et al., 2018; Zachry \& Schneider, 2010). Completing the requirement accounts for $10 \%$ of students' final course grades.

The first objective to investigate the efficacy of a supplemental support requirement on the passing rates of students in their first-year math courses was completed using descriptive analysis and predicative analytics. With $49 \%$ of students completing the midterm supplemental support target of nine hours in the Mathematics Achievement Center and $48 \%$ of students completing the final supplemental support target of 18 hours, our descriptive analysis revealed that fulfillment of the required supplemental support by both the midterm and final targets was an important factor in the prediction of midterm and final course grades. 
The second objective was to model the subgroup within the student population who met or exceeded the midterm supplemental support target. The CART model classifies final outcomes in first-year math courses based on the additional amount of supplemental support students accrued in the Mathematics Achievement Center beyond the midterm target of 540 minutes. We identified patterns that suggest ways to identify students at risk of failing their first-year math course. All students meeting the midterm supplemental support target have a chance to successfully complete their first-year math course. If their midterm course grade is at least $D$ and they continue receiving supplemental support in the Mathematics Achievement Center, they have a $99 \%$ chance of passing their course, while students with a midterm course grade of $\mathrm{F}$ or I have a $67 \%$ chance.

The third objective, to provide succinct conclusions that will motivate students to complete the supplemental support requirement, is now viable. By doing a better job of informing our students of both their goals and responsibilities, we can better evaluate their performance while concomitantly increasing success of the students (Grunert, Millis, \& Cohen, 2008). The datadriven guideline given by the CART model will arm instructors with additional means of encouraging their students to meet the midterm supplemental support target of nine hours. Students will frequently be informed by their math professor and tutors in the Mathematics Achievement Center that:

1. Students who complete at least nine hours of supplemental support in the Mathematics Achievement Center by the midterm target, earn a midterm course grade of at least $D$, and continue to receive the supplemental support in the Mathematics Achievement Center have a $99 \%$ chance of passing their first-year math course.

2. Students who complete at least nine hours of supplemental support in the Mathematics Achievement Center by the midterm target and earn a midterm course grade of $\mathrm{F}$ or I still have a $67 \%$ chance of passing their first-year course if they continue to receive approximately 10 hours of supplemental support in the Mathematics Achievement Center.

Our investigation of interventions in first-year math courses in higher education provides evidence for the effectiveness of supplemental support. This study provides a roadmap for student interventions and increasing student success with first-year mathematics courses.

\section{References}

Ambrose, S. A., Bridges, M. W., Lovett, M. C., DiPietro, M., \& Norman, M. K. (2010). How learning works: Seven research-based principles for smart teaching. San Francisco, CA: JosseyBass.

Anthony, G. \& Walshaw, M. (2009). Characteristics of effective teaching of mathematics: A view from the west. Journal of Mathematics Education, 2(2), 147-164.

Berry, R. Q., Thunder, K., \& McClain, O. (2011). Counter narratives: Examining the mathematics and racial identities of black boys who are successful with school mathematics. Journal of African American Males in Education, 2(1), 10-23.

Bloom, B. (1976). Human characteristics and school learning. New York, NY: McGraw-Hill Book Company.

Boylan, H. R. (2011). Improving success in developmental mathematics: An interview with Paul Nolting. Journal of Developmental Education, 34(3), 20-27.

Brakoniecki, L., Fitzgerald, K., \& Pritchard, A. (2013). An analysis of summer and fall 2013 developmental education pilots in Connecticut community colleges. Retrieved from http://www.ct.edu/initiatives/dev-education 
Breiman, L., Friedman, J., Olshen, R., \& Stone, C. (1984). Classification and regression trees. Boca Raton, FL: Chapman \& Hall/CRC Press.

Brock, T., Davis J., Todd E., Miller, J., Gooden, S., Martin, K., MacGregor, C., and Pih, M. (2007). Building a Culture of Evidence for Community College Student Success: Early Progress in the Achieving the Dream Initiative. New York: MDRC. Retrieved from https://www.mdrc.org/publication/building-culture-evidence-community-college-studentsuccess

Charalambos, C. Y. \& Hill, H. C. (2012). Teacher knowledge, curriculum materials, and quality of instruction: Unpacking a complex relationship. Journal of Curriculum Studies 44(4), 443466. http://dx.doi.org/10.1080/00220272.2011.650215

Cohen, R. \& Kelly, A. M. (2019). The impact of community college science and mathematics coursetaking on graduation, transfer, and non-completion. The Review of Higher Education 42(2), 595-617.

ConnCas. (2013). Connecticut College Access and Success Program Narrative Retrieved from www.ctohe.org

ConnSCU. (2014). Connecticut State Colleges and Universities Developmental Education (PA 12-40). Retrieved from http://www.ct.edu/initiatives/dev-education

Cornick, J., Guy, G. M., \& Beckford, I. (2015). Integrating study skills and problem solving into developmental mathematics. Teaching Mathematics and Its Applications: International Journal of the IMA, 34(2) 83-90. Doi: 10.1093/teamat/hru028

Ganga, E., Mazzariello, A., \& Edgecombe, N. (2018). Developmental education: An introduction for policymakers. Education Commission of the States, The Center for the Analysis of Postsecondary Readiness (CAPR). Retrieved from https://www.ecs.org/

Grunert O'Brien., J. G., Millis, B. J., \& Cohen, M. W. (2008). The course syllabus: A learningcentered approach (2nd ed.). San Francisco, CA: Jossey-Bass.

Guy, G. M., Cornick, J., \& Beckford, I. (2015). More than math: On the affective domain in developmental mathematics. International Journal for the Scholarship of Teaching and Learning 9(2), Article 7. Retrieved from https://doi.org/10.20429/ijsotl.2015.090207

Harvey K. \& Horton, L (1977). Bloom's human characteristics and school learning. The Phi Delta Kappan, 59(3), 189-193.

Hattie, J. \& Timperley, L. (2007). The power of feedback. Review of Educational Research, 77(1), 81-113.

Hodara, M. (2011). Reforming mathematics classroom pedagogy: Evidence-based findings and recommendations for the developmental math classroom (working paper). Retrieved from https://ccrc.tc.columbia.edu/publications/improving-students-college-math-readinesscapsee.html

Hodara, M. (2013). Improving students' college math readiness: A review of the evidence on postsecondary interventions and reforms (working paper). Retrieved from https://ccrc.tc.columbia.edu/publications/improving-students-college-math-readinesscapsee.html

Kezar, A., Gehrke, S., Bernstein-Sierra, S. \& Hunter, R. (2017). Designing for success in STEM communities of practice: Philosophy and personal interactions. The Review of Higher Education 40(2), 217-244. John Hopkins University Press. Retrieved from https://doi.org/10.1353/rhe.2017.0002

Koirala, H. P., Davis, M. J. \& Cid, C. R. (2010). Retention of most-at-risk entering students at a four year college. NERA Conference Proceedings 2010.30, Rocky Hill, Connecticut. Retrieved from http://digitalcommons.ucon.edu/near 2010/30

Kwenda, M. N. (2014). Tracking and explaining credit-hour completion. Higher Learning Research Communications, 4(1), 46-56. http://dx.doi.org/10.18870/hlrc.v4i1.132

Larose, D. T., \& Larose, C. D. (2015). Data Mining and Predictive Analytics, (2nd ed.). Chichester: Wiley-Blackwell. 
Nolting, P. D. (2008). Winning at math: Your guide to learning mathematics through successful study skills. (5th ed.). Florida: Academic Success Press, Inc.

Olango, M. (2015). Effects of selected affective variables on mathematics achievement of freshmen science and engineering students: The case of Hawassa University. African Educational Research Journal, 3(4), 255-268.

Raudenbush, S. W. (2008). Advancing educational policy by advancing research on instruction. American Educational Research Journal, 45(1), 206-230.

Reyes, L. H. (1984). Affective variables and mathematics education. The Elementary School Journal, 84(5), 558-581.

Rutschow, E. Z. \& Schneider, E. (2011). Unlocking the gate: What we know about improving developmental education. MDRC. Retrieved from https://www2.ed.gov/about/offices/list/opepd/education-strategies.pdf

Schak, O., Metzger, I., Bass, J., McCann, C. \& English, J. (2017). Developmental education challenges and strategies for reform. U. S. Department of Education. Retrieved from https://www2.ed.gov/about/offices/list/opepd/education-strategies.pdf

Sedlacek, W. E. (2004). Beyond the big test: Noncognitive assessment in higher education. San Francisco, CA: Jossey-Bass.

Senack, E., Donoghue, R., Grant, K. O., \& Steen, K. (2016). Access denied: The new face of the textbook monopoly. Student Organizing, Inc. Retrieved from www.studentpirgs.org/textbooks

Spaho, A. (2014). Factors impacting general mathematics success for first-year business' students: Evidence from Albania. Journal of Educational and Social Research, 4(2), 1116. Doi: $10.5901 /$ jesr.2014v4n2p11

Therneau, T., Atkinson, B., \& Ripley, B. (2017). rpart: Recursive partitioning and regression trees. $\mathrm{R}$ package version 4,1-11. https://CRAN.R-project.org/package=rpart

The IRIS Center. (2017). High-quality mathematics instruction: What teachers should know. Retrieved from https://iris.peabody.vanderbilt.edu/module/math/

Treisman, U. (1992). Studying students studying calculus: A look at the lives of minority mathematics students in college. The College Mathematics Journal, 23(5), 362-372.

Whiton, J. C., Rethinam, V., \& Preuss, M. D. (2018). Higher school factors predicting enrollment in developmental courses. Journal of Developmental Education. 42(1), 8-32.

Wright, B. L. (2009). Racial-ethnic identity, academic achievement and African American males: A review of literature. The Journal of Negro Education. 78(2), 123-134.

Zachry, E. M., \& Schneider, E. (2010). Building foundations for student readiness: A review of rigorous research and promising trends in developmental education. (An NCPR working paper.) Washington D.C.: National Center for Postsecondary Research. 